\title{
Does Malocclusion Severity affect the Psychosocial Impact of Dental Aesthetics among Nigerian Adolescents?
}

\author{
Akpasa Izegboya ${ }^{1}$, Yemitan Tolulase $1,2,{ }^{*}$, Aikins Elfleda ${ }^{3}$ and Popoola Bamidele 4 \\ ${ }^{1}$ Department of Child Dental Health, Lagos State University Teaching Hospital, Lagos, Nigeria. \\ 2 Department of Child Dental Health, Faculty of Dentistry, Lagos State University College of Medicine, Lagos, Nigeria. \\ 3 Department of Child Dental Health, University of Port Harcourt / University of Port Harcourt Teaching Hospital, Port \\ Harcourt, Rivers State, Nigeria. \\ ${ }^{4}$ Department of Child Oral Health, University College Hospital, Ibadan, Oyo State, Nigeria.
}

International Journal of Biological and Pharmaceutical Sciences Archive, 2022, 03(01), 040-047

Publication history: Received on 04 January 2022; revised on 08 February 2022; accepted on 10 February 2022

Article DOI: https://doi.org/10.53771/ijbpsa.2022.3.1.0027

\begin{abstract}
The impact of malocclusion on the psyche of an individual could range from mild reservations about teeth appearance to debilitating anxiety about self-image and self-esteem. The purpose of this study was to evaluate the psychosocial impact of malocclusion, determine its association with severity of malocclusion, and assess the effect of gender, age and academic level on psychosocial impact of malocclusion in Nigerian adolescents. A cross-sectional study was conducted on a random sample of 96 adolescents with an age range of 13 to 19 years recruited from patients at a hospital dental clinic in Lagos, Nigeria. A questionnaire was administered having sociodemographic section and the English version of the standardized questionnaire measuring the Psychosocial Impact of Dental Aesthetics (PIDAQ). The participants were assessed clinically and categorized into four malocclusion severity levels based on their Dental Aesthetic Index (DAI) scores. Descriptive statistics was used to describe the sample's sociodemographic characteristics as well as the mean PIDAQ and DAI scores. Bivariate analysis (ANOVA) was used to investigate the impact of the DAI scores on the mean PIDAQ scores. The interrelation among DAI and PIDAQ was analyzed using correlation analysis. The mean PIDAQ score was $42.5 \pm 11.0$. Severity of malocclusion as measured by DAI had no significant effect on psychosocial impact of dental aesthetics. The total PIDAQ score and its subscales showed no significant differences ( $p>0.05$ ) by age, gender, and academic level. Malocclusion severity has no significant linear relationship with the psychosocial impact of malocclusion.
\end{abstract}

Keywords: Malocclusion; Psychology; Quality of life; Adolescence

\section{Introduction}

The aesthetic appearance of an individual influence the psychosocial status and can affect the social integration of an adolescent into the society or influence the acceptance of such individual into a social circle.

Dental aesthetics is the cosmetic look of the teeth and a significant factor of psychological, emotional, and social wellbeing [1]. Physical appearance is a crucial factor in people's lives, and orofacial aesthetics may have a big impact, especially when it comes to social interactions [2]. Therefore, regardless of whether there is a meaningful functional or aesthetic impairment, the perception of dentition features such as tooth color, shape, size, and position may become psychosocially important [2].

\footnotetext{
${ }^{*}$ Corresponding author: Yemitan Tolulase

Department of Child Dental Health, Faculty of Dentistry, Lagos State University College of Medicine, Lagos, Nigeria. 
Malocclusion can be described as a physical handicap when it limits a person's social stereotype and opportunities [3]. Social and appearance norms set by peers and community may impact on individuals significantly [4] resulting in lack of self-esteem related to appearance with a sense of inferiority, thus having a negative impact on their quality of life [5].

Traditional methods of estimating orthodontic treatment need are mainly based on assessment of normative need with occlusal indices or cephalometric measurements [6,7]. These measures reflect only the viewpoint of professionals, rather than consumer expectations. This is however a shortcoming, because there are considerable differences between professional and patient perceptions of dental appearance and the need for orthodontic intervention $[1,6,8]$.

An instrument often used to assess malocclusion and orthodontic treatment needs is the Dental Aesthetic Index (DAI) [9] but it does not give any information about how malocclusion affects a patient's self-image and quality of life in terms of subjective well-being and daily functioning [10]. This led to the introduction of psychometric instruments that measure oral health-related quality-of-life (OHRQOL) outcomes [10-11] during the orthodontic treatment planning process. The Psychosocial Impact of Dental Aesthetics Questionnaire (PIDAQ) was created as an OHRQoL psychometric tool to assess the apparent effects that dental aesthetic concerns of patients have on their self-esteem [8]. It is made up of four subscales including Dental Self-Confidence (DSC), Social Impact (SI), Psychological Impact (PI) and Aesthetic Concern (AC).

Body image plays an important role in psychological, social adjustment and educational success among adolescents which makes them a relevant age group for the study of aesthetic perceptions and OHRQOL outcomes [12].

Among different nationalities, several research works has been done relating factors like age, gender, educational level, level of income and severity of malocclusion with psychosocial Impact of dental aesthetics [13-16]. In Nigeria, there have been very few studies of the psychosocial impact of malocclusion $[1,17,18]$. This paucity of research-based information is a barrier to the development and implementation of public policy aimed at the integration of multiple dimensions of health care, such as improvement in quality of life and self-image related to body satisfaction, effectiveness of intervention, and cost/benefit assessments [19,20].

Thus, the aim of this study was to investigate the effect of severity of malocclusion on psychosocial impact of malocclusion in a sample of adolescents.

\section{Material and methods}

\subsection{Study Population}

The subjects were adolescents recruited from patients who visited Lagos State University Teaching Hospital dental outpatients' clinic between March and December 2019.

\subsection{Inclusion Criteria}

Adolescents between the ages of 13 - 19 years who are of Nigerian descent, have not undergone any orthodontic therapy and gave consent to participate in the study.

\subsection{Exclusion Criteria}

Adolescents who have undergone orthodontic treatment or any major maxillofacial surgical/ reconstructive procedure; those who have facial asymmetry or deformities; those with visual/hearing impairment, physical deformities, autism, and those with history of trauma to their anterior teeth, whose anterior teeth presented visible caries lesions, dental hypoplasia or fluorotic lesions were excluded from the analysis.

\subsection{Study Design}

A cross-sectional descriptive study using convenient sampling of consecutive patients who presented at the dental clinic for oral diagnosis. The final sample included questionnaires from 96 patients.

\subsection{Questionnaire}

A questionnaire was administered having 2 sections, namely sociodemographic, and the standardized questionnaire measuring the Psychosocial Impact of Dental Aesthetics (PIDAQ). 
The Psychosocial Impact of Dental Aesthetics Questionnaire (PIDAQ) [8] was developed to evaluate self-perception of dental aesthetics and evaluate the psychosocial influence of dental aesthetics in adolescents seeking treatment. It is a validated self-rating 23-item tool that measures important aspects of the oral health-related quality of life, Dental Selfconfidence (DSC), Social Impact (SI), Psychological Impact (PI), and Aesthetic Concerns (AC).

It is made up of four subscales which represent 4 domains: aesthetic concern (AC; 3 items), psychological impact (PI; 6 items), social impact (SI; 8 items) and dental self-confidence (DSC; 6 items). A five-point Likert scale is used, ranging from 0 (no impact of dental aesthetics on quality of life) to 4 (maximal impact of dental aesthetics) for each item (Table 1). The response options are as follows: $0=$ not at all; $1=$ a little; $2=$ somewhat; 3 = strongly; and $4=$ very strongly. The DSC, SI, PI, AC scores were calculated by summing the participants' responses from the corresponding question items of each domain in the questionnaire. To ensure the same direction of scoring for all questionnaire items and to produce a consistent measure of impacts, the items in dental self-confidence (DSC) were scored in a reversed mode. Additionally, the total PIDAQ score was calculated from the sum scores of the subdivisions AC, PI, SI, and the reversed scores of the positive domain DSC.

\subsection{Clinical Examination}

Clinical examinations were performed by a calibrated investigator. The students who were surveyed and were willing to participate in clinical examinations received malocclusion severity examination using the DAI [17]. They were then categorized into four malocclusion severity groups using their DAI scores+, normal or minimal malocclusion (DAI score of $\leq 25$ ), definite malocclusion (DAI score of 26 - 30), severe malocclusion (DAI score of 31 - 35), and handicapping malocclusion (DAI score $>35$ ).

\subsection{Measurement Reliability}

The PIDAQ and DAI measurements were repeated for twenty study participants two weeks after the initial measurements by the same examiner. Pearson's coefficient analysis was utilized to determine intra-examiner reliability.

\subsection{Data Analysis}

Data was analyzed with the IBM Statistical Package for Social Sciences (SPSS) for Windows Version 23.0. (IBM Corp., Armonk, NY, USA). To test the internal consistency of the instrument, Cronbach's alpha ( $\alpha$ ) was calculated for the scale as a whole and for each individual domain. Descriptive statistics of clinical characteristics and scores were obtained. Bivariate analysis was performed using ANOVA test and Pearson's correlation coefficient. Multiple linear regression analysis was used to test the influence of age, gender, academic level, and malocclusion severity on the PIDAQ scale and subscales. Statistical significance was put at a $5 \%$ level and a Confidence Interval of $95 \%$.

\section{Results and discussion}

Overall, 96 respondents met the inclusion criteria, of which $33.3 \%$ were male, and $66.7 \%$ were females. They were aged $13-19$ years with a mean age of $17.99 \pm 0.95$. Most students $(60.4 \%)$ had no treatment need or only a slight need (grade $1)$, and $4.2 \%(n=4)$ had very severe malocclusion (grade 4$)$.

Table 1 includes data on the clinical characteristics of subjects assessed using the DAI and PIDAQ. Reliability analysis showed that internal consistency was considered acceptable. Cronbach's alpha was 0.74 for PIDAQ (subscale alphas ranged from 0.82 to 0.90 ). The correlation for components of DAI was between 0.94 and 0.98 .

Subjects' perception scores of the PIDAQ scale and subscales (Table 2) were analyzed according to the grades of malocclusion severity based on the DAI scores. The overall and subscale PIDAQ scores showed no significant difference among groups based on DAI scores ( $\mathrm{P}>0.05)$.

Table 3 shows bivariate correlation between all continuous variables. No significant correlation was found between DAI scores and total or subscale PIDAQ scores ( $>$ > 0.05). Multiple linear regression analysis (Table 4) showed that the independent variable (DAI score) had no significant effects on patients' perceptions of the psychosocial impacts of dental esthetics $(p>0.05)$. Age, gender and academic level included in the regression models as control variables had no significant effects on patients' perceptions of the psychosocial impacts of dental esthetics.

The PIDAQ scale and subscales showed $R^{2}$ values $\left(R^{2}=0.03-0.05\right)$ indicating that the model accounted for $3 \%$ to $5 \%$ of the variance in perception scores. 
Table 1 Clinical Characteristics of Subjects as Assessed Using the DAI and PIDAQ

\begin{tabular}{|l|l|l|l|l|}
\hline Variable & Possible Range of Total Scores & N & Min - Max & Mean (SD) \\
\hline DAI & $\geq 13$ & 96 & $15-47$ & $24.23(6.25)$ \\
\hline Grade 1 & $13-25$ & 58 & $15-25$ & $20.16(2.83)$ \\
\hline Grade 2 & $26-30$ & 26 & $26-30$ & $28.08(1.35)$ \\
\hline Grade 3 & $31-35$ & 8 & $31-35$ & $32.25(1.49)$ \\
\hline Grade 4 & $\geq 36$ & 4 & $39-47$ & $42.25(3.59)$ \\
\hline PIDAQ & $0-69$ & 96 & $10-67$ & $42.53(11.03)$ \\
\hline Dental Self-Confidence & & & $1-24$ & $15.22(5.04)$ \\
\hline Social impact & & & $0-32$ & $12.29(7.75)$ \\
\hline Psychological impact & & & $0-22$ & $11.20(5.18)$ \\
\hline Aesthetic concern & & & $0-12$ & $3.81(3.01)$ \\
\hline
\end{tabular}

Table 2 Comparison of Means and Standard Deviations of PIDAQ Scale and Subscales According to DAI Grades of Malocclusion

\begin{tabular}{|l|c|c|c|c|c|}
\hline & \multicolumn{5}{|c|}{ DAI } \\
\hline Scale/Subscale & Grade 1 & Grade 2 & Grade 3 & Grade 4 & P* \\
\hline PIDAQ scale & $42.00(11.15)$ & $45.54(10.88)$ & $41.75(9.38)$ & $32.25(8.54)$ & $>0.05$ \\
\hline Dental self-confidence subscale & $14.76(5.00)$ & $15.77(5.09)$ & $15.25(5.57)$ & $18.25(4.57)$ & $>0.05$ \\
\hline Social impact subscale & $12.03(7.65)$ & $13.81(8.22)$ & $11.75(7.72)$ & $7.25(5.50)$ & $>0.05$ \\
\hline Psychological impact subscale & $11.41(5.26)$ & $11.42(4.97)$ & $11.50(4.50)$ & $6.00(5.83)$ & $>0.05$ \\
\hline Aesthetic concern subscale & $3.78(2.99)$ & $4.54(3.11)$ & $3.25(2.55)$ & $0.75(1.50)$ & $>0.05$ \\
\hline
\end{tabular}

*Analysis of variance test

Table 3 Analysis of Correlation Between PIDAQ scale /subscale variables and DAI score

\begin{tabular}{|l|c|c|c|c|c|c|}
\hline Variables & DAI score & PIDAQ & DSC & SI & PI & AC \\
\hline DAI score & 1 & -0.053 & 0.113 & -0.030 & -0.121 & -0.098 \\
\hline PIDAQ & -0.053 & 1 & $-0.437^{* *}$ & $0.905^{* *}$ & $0.799^{* *}$ & $0.692^{* *}$ \\
\hline DSC & 0.113 & $-0.437^{* *}$ & 1 & $-0.615^{* *}$ & $-0.624^{* *}$ & $-0.621^{* *}$ \\
\hline SI & -0.030 & $0.905^{* *}$ & $-0.615^{* *}$ & 1 & $0.662^{* *}$ & $0.633^{* *}$ \\
\hline PI & -0.121 & $0.799^{* *}$ & $-0.624^{* *}$ & $0.662^{* *}$ & 1 & $0.550^{* *}$ \\
\hline AC & -0.098 & $0.692^{* *}$ & $-0.621^{* *}$ & $0.633^{* *}$ & $0.550^{* *}$ & 1 \\
\hline
\end{tabular}

** Significant at $\mathrm{P}<0.01 ; \mathrm{PIDAQ}=$ overall PIDAQ scale; DSC = dental self-confidence subscale; $\mathrm{SI}=$ social impact subscale; PI = psychological impact subscale; $\mathrm{AC}=$ aesthetic concern subscale 
Table 4 Multiple Linear Regression for the Association of PIDAQ and Independent Variables

\begin{tabular}{|l|l|l|l|l|l|l|}
\hline Regression parameters & Independent variables & PIDAQ & DSC & SI & PI & AC \\
\hline Beta coefficient & Age $(\mathrm{y})$ & -0.092 & 0.126 & -0.150 & -0.054 & -0.073 \\
\hline & Gender & 0.052 & -0.053 & 0.020 & 0.090 & 0.071 \\
\hline & Academic level & -0.108 & -0.093 & -0.036 & -0.009 & -0.132 \\
\hline & DAI score & -0.076 & 0.105 & -0.044 & -0.126 & -0.124 \\
\hline $\mathrm{R}^{2}$ & & 0.04 & 0.03 & 0.03 & 0.03 & 0.05 \\
\hline $\mathrm{P}$ & & $>0.05$ & $>0.05$ & $>0.05$ & $>0.05$ & $>0,05$ \\
\hline
\end{tabular}

PIDAQ, overall PIDAQ scale; DSC indicates dental self-confidence subscale; SI, social impact subscale; PI, Psychological impact subscale; $\mathrm{AC}$, aesthetic concern subscale

\section{Discussion}

This study reveals that severity of malocclusion as measured by DAI has no significant effect on psychosocial impact of self-perceived dental aesthetics among Nigerian adolescents (Table 2).

Taylor et al. [21] showed a poor correlation between malocclusion and oral health related quality of life among 11-14 year old adolescents in the United States. Figueroa et al. [22] found a low direct correlation between the severity and psychosocial impact of malocclusion. In contrast, A systematic review of six cross-sectional studies [23] found a high level of evidence that severe malocclusions, especially in the aesthetic zone (anterior crowding, midline diastema, increased overjet), have negative effects on OHRQOL in children and adolescents, predominantly in the dimensions of emotional and social wellbeing [24-26].

There are several possible reasons for differences between our study and previous studies. First, the weak association between malocclusion severity and psychosocial impact of malocclusions in our sample (Table 2) may be due to the low prevalence of severe and handicapping malocclusions $4.2 \%(n=4)$ in our sample, because severe malocclusion has been reported to have a greater aesthetic and psychosocial impact [23-26] (Table 1). Secondly it is possible that the sample populations studied could have had different age groups with different perception towards aesthetics and quality of life. In addition, different cultures, traditions, and social norms across populations may influence the perception of aesthetics differently in each society. Furthermore, a high incidence of severe malocclusions in some population groups may make malocclusion perceived as normal [27]. The differences in results could also be due to the differences in orthodontic indices used in the different surveys. Some epidemiological indices of orthodontic treatment needs, including the DAI, have an aesthetic component based on clinical criteria such as occlusal and functional features that may not accurately represent patients' perceptions of their dental aesthetics. Because psychosocial impact of malocclusion is strongly influenced by personal expectations and sociocultural factors, malocclusions may not always be negatively self-perceived.

Studies have shown PIDAQ as a reliable and effective method for measuring the psychosocial impact of malocclusion [28]. Pearson's correlation coefficient showed a satisfactory association among PIDAQ scale and subscales (Table 3), suggesting that these indices do share some common traits in psychosocial impacts of malocclusion. However, the weakest correlation was found between PIDAQ scale / subscales and DAI (Table 3). Previous studies have shown that DAI had weak associations with psychosocial impact of malocclusion [29].

The present study shows no significant difference in patients' perceptions of the psychosocial impacts of dental esthetics due to gender, age or academic level (Table 4). This finding on gender influence is like results from other populations $[30,31]$, but differs from other studies that found that gender was an independent predictor of psychosocial impact of malocclusion, with more of the impact experienced by females [32,33]. This could be attributed to females being more appreciative of the social significance of aesthetics more than male counterparts.

Age did not have a significant effect on the psychosocial impact of the malocclusions of our study participants which is comparable to a study carried out among Spanish adolescents [34]. However, it differs from another study where age was found to play a role in the psychosocial impact that malocclusions had on the study participants [13]. Although not statistically significant, a negative association was observed between age and impact on quality of life due to malocclusion in the present study (Table 4), the impact of malocclusion decreases as age increases. This may be the 
result of 'response shift' with age, in which there is reduction in the impact of a malocclusion, when an individual lives longer with a malocclusion, due to the likelihood that they will adjust to the limitations it places upon their activities [35]. Academic level had a negative association in the regression analysis with reduction in the impact of malocclusion as academic level increases, though not statistically significant. This may be due to increased self-esteem with increasing education (Table 4).

The internal consistency of the PIDAQ in this study was good (Cronbach's coefficient, 0.74). However, the present study has some limitations that may limit the generalization of its results. The participants in this study were 13-19-year-old patients seeking dental or orthodontic treatment at a university clinic in a large urban city in Nigeria. The results from this study therefore cannot be generalized to the entire adolescent population who may have varying levels of malocclusion and orthodontic treatment needs and experiencing different impacts on their daily activities [36]. We therefore recommend that future studies should be based on a representative sample of adolescents in order to investigate the effect of cultural and societal norms on psychosocial impact of malocclusion.

\section{Conclusion}

This study has shown that severity of malocclusion has no significant association with perceived psychosocial impact of dental aesthetics. It also found that gender, age or academic level were not independent predictors of psychosocial impact of malocclusion. Therefore, evaluation of orthodontic treatment need using an approach that combines normative and psychosocial perception of occlusion is recommended in order to complement clinical findings with patients' perception.

\section{Compliance with ethical standards}

\section{Acknowledgments}

I wish to thank Boluwatife Oyewunmi for her help with data collection.

\section{Disclosure of conflict of interest}

The authors hereby declares that there's no conflict of interest and that we all agreed that the paper be published.

\section{Statement of ethical approval}

Ethical approval was obtained from the Health Research and Ethics Committee of the Lagos State University Teaching Hospital (LREC. 06/10/813).

\section{Statement of informed consent}

Following detailed explanation of the aims and objectives of the study, a written informed consent was taken from subjects 18 years and above as well as parents/guardians of the selected subjects below the age of 18 years who were willing to participate in the research. Written assent was similarly taken from the subjects below 18 years of age.

\section{References}

[1] Kanmodi KK, Nwafor JN, Iyadi LE, Eddah KI, Omoleke S. Psychosocial impact of dental aesthetics among secondary school students in Birnin Kebbi, Northern Nigeria: Population-based study. Med J Zambia. Oct 2020; 47(3): 197-203.

[2] Campos LA, Costa MA, Bonafé FSS, Marôco J, Campos JADB. Psychosocial impact of dental aesthetics on dental patients. Int Dent J. Oct 2020; 70(5): 321-7.

[3] AlSagob EI, Alkeait F, Alhaimy L, Alqahtani M, Hebbal M, Ben Gassem AA. Impact of Self-Perceived Dental Esthetic on Psycho-Social Well-Being and Dental Self Confidence: A Cross-Sectional Study Among Female Students in Riyadh City. Patient Prefer Adherence. May 2021; 15: 919-26.

[4] Cislaghi B, Heise L. Gender norms and social norms: differences, similarities and why they matter in prevention science. Sociol Health Illn. Dec 2020; 42(2): 407-22.

[5] Aikins EA, Onyeaso CO. Prevalence of malocclusion and occlusal traits among adolescents and young adults in Rivers State, Nigeria. Odontostomatol Trop. Mar 2014; 37(145): 5-12. 
[6] Azuma S, Kohzuki M, Saeki S, Tajima M, Igarashi K, Sugaware J. Beneficial effects of orthodontic treatment on quality of life in patients with malocclusion. Tohoku J Exp Med. 2008; 214: 39-50.

[7] Bernabé E, Tsakos G, De Oliveira CM, Sheiham A. Impacts on daily performances attributed to malocclusions using the condition-specific feature of the Oral Impacts on Daily Performances Index. Angle Orthod. Mar 2008; 78(2): 241-7.

[8] Pietilä T, Pietilä I. Dental appearance and orthodontic services assessed by 15-16-year-old adolescents in eastern Finland. Community Dent Health. Sep 1996; 13(3): 139-44.

[9] Bernabé E, Flores-Mir C. Orthodontic treatment need in Peruvian young adults evaluated through dental aesthetic index. Angle Orthod. May 2006; 76(3): 417-421.

[10] Hamdam AM, Al-Omari IK, Al-Bitar ZB. Ranking dental aesthetics and thresholds of treatment need: a comparison between patients, parents, and dentists. Eur J Orthod. Aug 2007; 29(4): 366-71.

[11] Gherunpong S, Tsakos G, Sheiham A. A socio-dental approach to assessing children's orthodontic needs. Eur J Orthod. Aug 2006; 28(4): 393-9.

[12] Klages U, Bruckner A, Zentner A. Dental aesthetics, self-awareness, and oral health-related quality of life in young adults. Eur J Orthod. Oct 2004; 26(5): 507-14.

[13] Ilijazi Shahiqi D, Dogan S, Krasniqi D, Ilijazi D, Anic Milosevic S. Psycho-social impact of malocclusion in adolescents in Kosovo. Community Dent Health. May 2021; 38(2): 71-5.

[14] Doğan AA, Sari E, Uskun E, Sağlam AM. Comparison of orthodontic treatment need by professionals and parents with different socio-demographic characteristics. Eur J Orthod. Mar 2010; 32(6): 672-6.

[15] Baram D, Yang Y, Ren C, Wang Z, Wong RWK, Hägg U, Gu M. Orthodontic treatment need and the psychosocial impact of malocclusion in 12-year-old Hong Kong children. Sci World J. 2019; 2685437.

[16] García Pérez A, González-Aragón Pineda ÁE, Gonzalez Olivares H. Oral health-related quality-of-life scores differ by socioeconomic status, mother's level of education, dental visits and severity of malocclusion in mixed dentition of eight-to-ten-year-old schoolchildren. PeerJ. Sep 2021; 9: e12062.

[17] Onyeaso C0, Sanu 00. Psychosocial implications of malocclusion among 12-18 year old secondary school children in Ibadan, Nigeria. Odontostomatol Trop. Mar 2005; 28(109): 39-48.

[18] Onyeaso CO, Utomi IL, Ibekwe TS. Emotional effects of malocclusion in Nigerian orthodontic patients. J Contemp Dent Pract. 15 Feb 2005; 6(1): 64-73.

[19] Hunt O, Hepper P, Johnston C, Stevenson M, Burden D. The Aesthetic Component of the Index of Orthodontic Treatment Need validated against lay opinion. Eur J Orthod. Feb 2002; 24(1): 53-9.

[20] Imani MM, Jalali A, Dinmohammadi M, Nouri P. The Effect of Orthodontic Intervention on Mental Health and Body Image. Open Access Maced J Med Sci. Jun 2018; 6(6): 1132-7.

[21] Taylor KR, Kiyak A, Huang GJ, Greenlee GM, Jolley CJ, King GJ. Effects of malocclusion and its treatment on the quality of life of adolescents. Am J Orthod Dentofacial Orthop. Sep 2009; 136(3): 382-92.

[22] Figueroa FR, Bancalari C, Cartes-Velásquez R, Sanhueza M, Palma C. Prevalence of Malocclusion and its Psychosocial Impact in a Sample of Chilean Adolescents Aged 14 to 18 years old. J Int Dent Med Res 2017; 10(1): 14-8.

[23] Dimberg L, Arnrup K, Bondemark L. The impact of malocclusion on the quality of life among children and adolescents: a systematic review of quantitative studies. Eur J Orthod. Jun 2015; 37(3): 238-47.

[24] Sardenberg F, Martins MT, Bendo CB, Pordeus IA, Paiva SM, Auad SM, Vale MP. Malocclusion and oral healthrelated quality of life in Brazilian school children. Angle Orthod. Jan 2013; 83(1): 83-9.

[25] Scapini A, Feldens CA, Ardenghi TM, Kramer PF. Malocclusion impacts adolescents' oral health-related quality of life. Angle Orthod. 2013 May; 83(3): 512-8.

[26] Ukra A, Foster Page LA, Thomson WM, Farella M, Tawse Smith A, Beck V. Impact of malocclusion on quality of life among New Zealand adolescents. N Z Dent J. Mar 2013; 109(1): 18-23.

[27] Heravi F, Farzanegan F, Tabatabaee M, Sadeghi M. Do malocclusions affect the oral health-related quality of life? Oral Health Prev Dent. 2011; 9(3): 229-33. 
[28] Kolawole KA, Agbaje HO, Otuyemi OD. Impact of malocclusion on oral health related quality of life of final year dental students. Odontostomatol Trop. Mar 2014; 37(145): 64-74.

[29] Ashari A, Mohamed AM. Relationship of the Dental Aesthetic Index to the oral health-related quality of life. Angle Orthod. March 2016; 86(2): 337-42.

[30] Palomares NB, Celeste RK, Oliveira BH, Miguel JA. How does orthodontic treatment affect young adults' oral health-related quality of life? Am J Orthod Dentofacial Orthop. Jun 2012; 141(6): 751-8.

[31] Wan Hassan WN, Yusof ZY, Shahidan SS, Mohd Ali SF, Makhbul MZ. Validation and reliability of the translated Malay version of the psychosocial impact of dental aesthetics questionnaire for adolescents. Health Qual Life Outcomes. 26 Jan 2017; 15(1): 23.

[32] Hamdan AM. The relationship between patient, parent and clinician perceived need and normative orthodontic treatment need. Eur J Orthod. Jun 2004; 26(3): 265-71.

[33] Bellot-Arcís C, Ferrer-Molina M, Carrasco-Tornero Á, Montiel-Company JM, Almerich-Silla JM. Differences in psychological traits between lingual and labial orthodontic patients: perfectionism, body image, and the impact of dental esthetics. Angle Orthod. Jan 2015; 85(1): 58-63.

[34] Iranzo-Cortés JE, Montiel-Company J. Bellot-Arcis, C. et al. Factors related to the psychological impact of malocclusion in adolescents. Sci Rep. 2020; 10: 13471.

[35] Ring L, Höfer S, Heuston F, Harris D, O'Boyle CA. Response shift masks the treatment impact on patient reported outcomes (PROs): the example of individual quality of life in edentulous patients. Health Qual Life Outcomes. 7 Sep 2005; 3: 55.

[36] Johal A, Cheung MY, Marcene W. The impact of two different malocclusion traits on quality of life. British Dental Journal. Jan 2007; 202(2): E2. 